\title{
Innovation Mechanism of Traffic Demand Management
}

\author{
Qingyin Li ${ }^{1, ~ *}$, Zhongjiao Xie ${ }^{2}$, Yongqing Guo ${ }^{1}$, Fulu Wei ${ }^{1}$, Yan Tian ${ }^{3}$, Yanfeng Zhang ${ }^{3}$, \\ Chaoran Wang ${ }^{1}$
}

${ }^{1}$ Department of Traffic Engineering, Shandong University of Technology, Zibo, China

${ }^{2}$ Shandong Public Security Bureau, Traffic Administration Bureau, Jinan, China

${ }^{3}$ Shandong Zibo Public Security Bureau, Zibo, China

Email address:

zbjjli@163.com (Qingyin Li)

${ }^{*}$ Corresponding author

\section{To cite this article:}

Qingyin Li, Zhongjiao Xie, Yongqing Guo, Fulu Wei, Yan Tian, Yanfeng Zhang, Chaoran Wang. Innovation Mechanism of Traffic Demand Management. American Journal of Traffic and Transportation Engineering. Vol. 4, No. 4, 2019, pp. 132-136.

doi: $10.11648 /$ j.ajtte.20190404.13

Received: July 7, 2019; Accepted: August 13, 2019; Published: August 26, 2019

\begin{abstract}
Traffic demand management is an effective way to solve the problem of urban traffic congestion. Due to the effects of the social economic development, population quality, scientific and technological level and other related factors, the existing traffic demand management systems are lack of effective coordination and management mechanism. Although the traffic demand management measures have achieved some results, but due to lack of effective coordination and management mechanism between them, resulting in poor practical application. By analyzing and summarizing the current situations of traffic demand management, the paper explores an innovative traffic demand management mechanism based on comprehensive traffic planning and modern information technology and economic means. Under the new demand management mechanism, the urban transportation system runs more orderly, which can help to largely increase residents' travel satisfaction and social and economic benefits. On the basis of analyzing and summarizing the current research status of traffic demand management, this paper conducts innovative research on traffic demand management mechanism based on the implementation effect of existing traffic demand management. In view of the existing shortcomings in the systematic and scientific traffic demand management, and insufficient traffic law enforcement quality problems, the paper explores the innovative traffic demand management mechanism based on comprehensive transportation planning, modern information technology and economic means.
\end{abstract}

Keywords: Traffic Congestion, Traffic Demand Management Mechanism, Innovation

\section{Introduction}

The problem of urban traffic congestion caused by the rapid development of urban economy has become a hot topic of discussion. In order to solve this problem, Domestic and international scholars have carried out a lot of research. Practice shows that traffic demand management [1-3] is an effective way to solve urban traffic congestion. Due to the effects of social and economic development, population quality, scientific and technological level and other factors, the existing traffic demand management systems are lack of effective coordination and management. So they cannot exert their maximum effectiveness. On the basis of analyzing and summarizing the current research status of traffic demand management [4], this paper conducts innovative research on traffic demand management mechanism [5-7] based on the implementation effect of existing traffic demand management. The specific ideas are shown in figure 1 below:

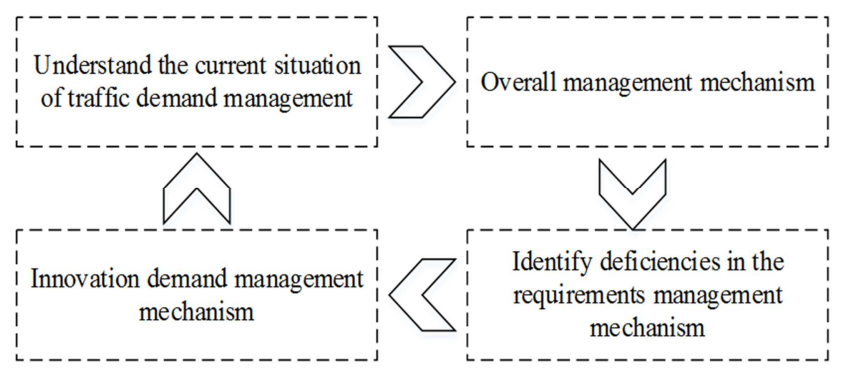

Figure 1. Research ideas of this paper. 


\section{Traffic Demand Management}

Traffic demand originates from human activities, and its distribution and intensity determine the traffic demand [8-9]. Traffic demand management originates from the shortage of resource supply. The primary goal of traffic demand management is to reduce or eliminate road traffic congestion.

The United States is the first country to start the study of traffic demand management [10-12]. After realizing that "only building roads cannot completely solve the problem of traffic congestion", its traffic engineering experts began to study traffic demand management strategies and policies. From the 1990s, the United States began to carry out comprehensive traffic research, combining traffic demand management with traffic planning, and emphasizing the important role of traffic demand management [13-14] again. In the early 1970s, Singapore obtained remarkable achievement by implementing vehicle ownership license system, ALS system, ERP system and other measures. China's Hong Kong and Japan have also carried out a lot of traffic demand management work.

Today, the traffic demand management is no longer stay in the management level of limiting the number of motor vehicles and vehicle travel restrictions [15], but it began to study reasonable area structure or sustainable comprehensive transportation system. Through a variety of policy, law, and modern information technology, the rational development of land resources, traffic demand management systems control, restrict and guide people to use limited traffic resource, in order to reduce travel, reduce travel time and space in the process of consumption, finally to establish a balanced urban traffic system.

The objectives of modern traffic demand management are shown as follows: 1. Ensure traffic safety and dredge traffic; 2 . Regulate traffic travel behavior according to traffic flow distribution, and reasonably guide the traffic travel mode, route and time of travelers by providing real-time traffic information, so as to reduce the total number of cars on the road, relieve congestion and ensure safety and smoothness.

Traffic demand management is a measure that manages the initiative to participate in the construction of traffic system, to control the hidden danger of road safety from the source, and to improve the quality of road participants from education. According to the different nature and connotation of traffic demand management, traffic demand management can be divided into three categories:

1) Traffic administration --the government and traffic administrative agencies should, within the scope prescribed by relevant laws, make decisions, plan, organize, lead, supervise and control traffic affairs.

2) Traffic order (law enforcement) management --conduct reasonable guidance, restriction, organization and coordination of traffic flow, people flow and other traffic-related activities on roads in accordance with traffic laws and regulations.

3) Traffic operation management --use traffic technical measures to carry out organized coordination and processing activities of the traffic system.

\section{Analyzing Traffic Demand Management Mechanism and Diagnosing Traffic Problems}

\subsection{Traffic Demand Management Mechanism}

Traffic demand management mechanism refers to the internal working mode of management activities related to urban traffic, including the relationship between the components of the management structure, as well as the transmission mode and constraint conditions of the interaction among them. Obviously, urban traffic demand management is not only a management system, but it covers all aspects of urban traffic. An effective management mechanism requires harmonious management activities at the macro, meso and micro levels, rather than contradictory each other.

\subsection{Mechanism Composition}

A complete management mechanism is the precondition to ensure the orderly operation of urban traffic system. The key step is to establish a benign and interactive urban traffic demand management mechanism to build a management system framework that conforms to the national conditions. It is reasonable in structure, establishes a legal management system and mechanism for urban traffic, and coordinates the management of various departments under the premise of fully understanding the status and role of urban traffic. Table 1 shows the functions, implementation stages and information requirements of different demand management measures.

Table 1. Functions, implementation stages and information requirements of different demand management measures.

\begin{tabular}{|c|c|c|c|c|}
\hline No. & Demand Management Measures & Effect & Implementation phase & Information needs \\
\hline 1 & Land use & $\begin{array}{l}\text { Change the traffic distribution } \\
\text { pattern, reduce traffic occurrence } \\
\text { and attraction }\end{array}$ & City planning & $\begin{array}{l}\text { The Natural Conditions, Historical } \\
\text { Conditions, Current Situation and } \\
\text { Construction Conditions of the Region }\end{array}$ \\
\hline 2 & Road planning & $\begin{array}{l}\text { To provide decision-making basis } \\
\text { for the short-term and long-term } \\
\text { development and construction of } \\
\text { regional roads by formulating } \\
\text { reasonable and feasible planning } \\
\text { plan and construction schedule }\end{array}$ & Traffic planning & $\begin{array}{l}\text { Economic Background and Population } \\
\text { Statistics, Transportation System } \\
\text { Management Information, } \\
\text { Transportation Conditions, Land Use } \\
\text { Management and Environmental } \\
\text { Conditions }\end{array}$ \\
\hline 3 & $\begin{array}{l}\text { Traffic Information and Route } \\
\text { Guidance }\end{array}$ & $\begin{array}{l}\text { Reduce blindness in choosing } \\
\text { travel time, mode or route }\end{array}$ & $\begin{array}{l}\text { Travel Generation, Travel } \\
\text { Distribution, Travel Mode } \\
\text { Selection and Route }\end{array}$ & $\begin{array}{l}\text { Route guidance and road condition } \\
\text { information }\end{array}$ \\
\hline
\end{tabular}




\begin{tabular}{|c|c|c|c|c|}
\hline No. & Demand Management Measures & Effect & Implementation phase & Information needs \\
\hline & & & Selection Phase & \\
\hline 4 & Parking management & $\begin{array}{l}\text { Reducing the number of private } \\
\text { car trips through parking fees and } \\
\text { parking lot construction } \\
\text { management }\end{array}$ & $\begin{array}{l}\text { Travel Generation, } \\
\text { Distribution and Mode } \\
\text { Selection Phase }\end{array}$ & $\begin{array}{l}\text { Parking fee section and price, parking } \\
\text { location and number of empty parking } \\
\text { spaces }\end{array}$ \\
\hline 5 & employment management of vehicle & $\begin{array}{l}\text { Restrain the traffic demand for } \\
\text { cars and get financial subsidies }\end{array}$ & $\begin{array}{l}\text { Travel Generation, Travel } \\
\text { Distribution, Travel Mode } \\
\text { Selection and Route } \\
\text { Selection Phase }\end{array}$ & $\begin{array}{l}\text { Road condition information, such as } \\
\text { congestion section, degree of } \\
\text { congestion, etc. }\end{array}$ \\
\hline 6 & Guiding Travel Behavior & $\begin{array}{l}\text { Reduce the number of car trips } \\
\text { during rush hours }\end{array}$ & $\begin{array}{l}\text { Travel Distribution and } \\
\text { Travel Mode Selection } \\
\text { Phase }\end{array}$ & Target population \\
\hline 7 & Parking and transfer & $\begin{array}{l}\text { Reducing the number of cars } \\
\text { entering the urban central area, } \\
\text { alleviating road congestion, } \\
\text { improving travel efficiency and } \\
\text { improving the transportation } \\
\text { system }\end{array}$ & Travel mode selection stage & $\begin{array}{l}\text { Travelers'gender, age, occupation, } \\
\text { income, place of departure, } \\
\text { destination, purpose, cost and time of } \\
\text { travel }\end{array}$ \\
\hline
\end{tabular}

With the development and application of information technology and network technology, the demand of urban traffic produces new characteristics.

1) Virtualization of traffic demand

With the rapid development of information technology, human society has entered the network information era, and a large number of activities can be realized through the network. At present, many countries and cities have appeared teleconferencing, home office, online services (such as online education, online medical treatment, online entertainment, etc.), information transmission, etc. These network activities virtualize part of the traffic demand, thereby reducing the amount of travel and easing the pressure of road traffic facilities.

2) More orderly traffic demand

In the traditional travel, people, as the main body of travel, decide the travel mode, route and time based on their personal travel desire, subjective experience of traffic conditions and travel routes, simple traffic information notification and other limited means. In the information society, the transportation system composed of computer technology, communication technology, global positioning technology, geographic information technology and other high-tech electronic information technology provides rich and real-time traffic information for travelers. At the same time, the government implements relevant traffic strategies, so that the optimized travel will be more orderly.

3) Diversity of traffic demand

With the improvement of the transportation system, people have more and more options to travel. The diversification of traffic system and abundant real-time traffic information ensure the diversification of travel. In different stages of travel, people can get the required travel information through various channels. Dynamic information acquired before and during travel can influence travelers' choice or decision, and travelers can choose or change travel route, mode and travel time more conveniently and quickly than before.

4) Dependency on traffic demand

The dynamic information provided by the traffic system has a lasting impact on the travelers, which is the embodiment of the traffic demand dependency. People judge things by repeated practice, and once an impression is formed, which is not easy to change. Therefore, travelers who make travel decisions under the guidance of traffic information can quickly evaluate traffic information and decide whether to adopt the recommended scheme or not after practical verification. After multiple applications, travelers will actively rely on the provision of traffic information for their travel choices and decisions.

Therefore, at present, many traffic management departments have introduced and developed urban traffic information system, combining strategy with information supply, so as to better improve urban traffic environment and facilitate people to travel.

5) The impact of emerging characteristics of traffic demand on traffic demand management

The above analysis of the emerging characteristics of traffic demand is to find the starting point of traffic demand management. Table 2 shows a summary of the impact of the emerging characteristics of traffic demand on traffic demand management.

Table 2. The impact of emerging characteristics of traffic demand on traffic demand management.

\begin{tabular}{lll}
\hline $\begin{array}{l}\text { Sequence } \\
\text { Number }\end{array}$ & The Impact of Emerging Traffic Demand & Characteristics on Traffic Demand Management \\
\hline 1 & Demand virtualization & Promote the implementation of home work measures and reduce traffic demand \\
2 & Demand more orderly & Facilitating public recognition and support for traffic demand management measures \\
3 & Flexibility & Favorable to guide travel reasonably with guidance information \\
4 & Effective combination of travel & Effective combination of travel \\
5 & Dependence & Facilitating the Implementation and Popularization of Information Induction \\
\hline
\end{tabular}


In practical application, single strategy or combination of multiple strategies can be selected according to the needs of the target city to achieve the expected effect.

\subsection{Problem Diagnosis of Traffic Demand Management Mechanism}

Traffic is a huge complex system, involving all aspects of social life. The shortcomings of the existing traffic demand management mechanism are as follows: most of the traffic demand management measures are proposed by various departments from their own perspectives based on their own experience, lack of systematisms and scientificity. Therefore, the implementation effect is not good enough. In addition, some urban traffic managers and some residents have insufficient traffic literacy, making it difficult to implement many effective traffic demand management measures.

\section{Research on Innovative Mechanism of Traffic Demand Management}

The Innovative traffic management mechanism is that the new urban traffic situation endows traffic engineers with a new historical mission. It can not only promote the reengineering of management organization and the optimization of business process, but also improve the scientific decision-making level of traffic management. Moreover, it can strengthen the coordination and communication between the functional departments of the transportation system, and effectively avoid the unbalanced development and bottleneck problems of the transportation system, which is conducive to the construction of harmonious transportation. Harmonious road traffic environment is related to people's life and property safety and the healthy development of economy and society. To build a harmonious traffic environment, it is necessary to implement the construction of service-oriented government in the human-vehicle-road-environment system in accordance with the "people-oriented" management concept, ensure the safety of traffic activities of the masses and the quality of traffic service, and realize the multi-coordination and joint management of traffic.

Traffic activities come from differences in the nature of land use, and traffic behaviors in the process of travel are also affected by factors such as real-time road conditions and travel costs. The innovative research on traffic demand management mechanism should be traced back to the source and start from the source of traffic occurrence, that is to say, the coordination mechanism in comprehensive traffic planning should be the main part. Secondly, modern information technology and economic means should be supplemented to improve the scientificity and effectiveness of traffic demand management mechanism.

\subsection{Research on Coordination Mechanism Innovation in Comprehensive Transportation Planning}

In the comprehensive transportation planning of the city, the work should be carried out from the two important aspects of land use, division of labor among various departments and coordination mechanism. I In the process of urban planning and transport planning feedback mechanism, integrated planning and quantitative analysis, determine the urban development pattern, the industry layout, land function zoning, and function design, etc. In the comprehensive transportation planning of land use planning at the same time, coordinate transportation and land use planning, clarify the responsibilities of various departments and coordination mechanism between departments.

\subsection{Application of Modern Information Technology in Traffic Demand Management}

In the travel activities of urban residents, the choices of travel time, travel mode and travel route are mostly based on their travel habits and travel purposes. Although many travel assistance systems developed based on modern high-tech have been around for a long time, there are still some obstacles in the development of modern information technology in the transportation industry due to the problems of software itself and the limitations of people's understanding to accept new things. On the other hand, it is possible that when travelers travel in accordance with the traffic information obtained, the otherwise uncrowded roads may become crowded, while the otherwise crowded roads may become uncrowded. As a result, the congestion of roads is not really alleviated, and only the time or place are shifted.

Therefore, attentions must be paid to the development or adoption of traffic information and route guidance systems with crowd-state (time-dependent) prediction functions that do not result in congestion transfer.

\subsection{Application of Economic Means in Traffic Demand Management}

Some experts classify traffic behavior as a branch of economic activity, and scientific and reasonable economic means can alleviate urban traffic congestion to a certain extent. Traditional congestion charging system and parking charge system achieved some effects in specific time, place, but due to the regional differences, it is difficult to widely apply. Therefore, it is need to adjust measures to local conditions of the corresponding policy, in order to obtain ideal results.

\subsection{Application of Eliminating Departmental Information Barriers in Traffic Demand Management}

Some government departments actively establish innovation mechanism, in the pursuit of social efficiency, satisfy the people life convenient at the same time. The objective is to reduce the traffic demand of the masses, such as the medical system strongly supported by traffic police in Shandong Zibo city. This system puts every accident insurance, medical treatment, the police handling of import system in time, the parties know the details of the case through the system, reduces the round-trip consulting the traffic 
demand of each department; For example, for illegal overloaded trucks seized in the process of law enforcement, we can optimize the mode of transport: overloaded railway transport of sand, stone, steel; In addition, the construction of bus, subway and light rail should be strengthened, and the design of lines should be optimized to make the transportation more convenient and economical than that of the family travel, which can significantly reduce the traffic demand.

\section{Conclusion}

In view of the existing shortcomings in the systematic and scientific traffic demand management, and insufficient traffic law enforcement quality problems, this article explored the innovative traffic demand management mechanism based on comprehensive transportation planning, modern information technology and economic means. The ability of making full use of the transportation system has been effectively in reducing unnecessary traffic delay, reducing travel time and increasing traffic safety. In order to ensure the orderly operation of the urban traffic system, and to help promote residents' satisfaction and social and economic benefits.

\section{References}

[1] Jorge M. Bandeira, Dário O. Carvalho, Asad J. Khattak, et al. Empirical assessment of route choice impact on emissions over different road types, traffic demands, and driving scenarios [J]. International Journal of Sustainable Transportation, 2016, 10 (3): $271-283$.

[2] Yihang Zhang, Petros A. Ioannou. Combined Variable Speed Limit and Lane Change Control for Highway Traffic [J]. IEEE Transactions on Intelligent Transportation Systems, 2016, 18 (7): 1812-1823.

[3] Michele Mangili, Jocelyne Elias, Fabio Martignon, Antonio Capone. Optimal planning of virtual content delivery networks under uncertain traffic demands [J]. Computer Networks, 2016, 106: 186-195.

[4] Jinghuan Ma, Lingyang Song, Yonghui Li. Cost Efficiency for Economical Mobile Data Traffic Management from Users' Perspective [J]. IEEE Transactions on Wireless Communications, 2016, 16 (1): 362-375.
[5] Xiangjie Kong, Zhenzhen Xu, Guojiang Shen, et al. Urban traffic congestion estimation and prediction based on floating car trajectory data [J]. Future Generation Computer Systems, 2016, 61: 97-107.

[6] Yiyong Xiao, Abdullah Konak. The heterogeneous green vehicle routing and scheduling problem with time-varying traffic congestion [J]. Transportation Research Part E: Logistics and Transportation Review, 2016, 88: 146-166.

[7] Shen Wang, Soufiene Djahel, Zonghua Zhang, Jennifer McManis. Next Road Rerouting: A Multiagent System for Mitigating Unexpected Urban Traffic Congestion [J]. IEEE Transactions on Intelligent Transportation Systems, 2016, 17 (10): 2888-2899.

[8] Dongfang Ma, Xiaoqin Luo, Wenjing Li, Sheng Jin, Weiwei Guo, Dianhai Wang. Traffic demand estimation for lane groups at signal-controlled intersections using travel times from video-imaging detectors [J]. IET Intelligent Transport Systems, 2017, 11 (4): 222-229.

[9] Lara Codeca, Raphael Frank, Sebastien Faye, Thomas Engel. Luxembourg SUMO Traffic (LuST) Scenario: Traffic Demand Evaluation [J]. IEEE Intelligent Transportation Systems Magazine, 2017, 9 (2): 52-63.

[10] Eleonora D'Andrea, Francesco Marcelloni. Detection of traffic congestion and incidents from GPS trace analysis [J]. Expert Systems with Applications, 2017, 73: 43-56.

[11] Wei Deng, Yi Yuan, Shanlong Jiang. Bus passenger flow statistics method based on IC card historical data [J]. Urban public transport, 2017 (5): 21-24.

[12] Qiu Shen, Zhan Ma, Shaowei Wang. Deploying C-RAN in Cellular Radio Networks: An Efficient Way to Meet Future Traffic Demands [J]. IEEE Transactions on Vehicular Technology, 2018, 67 (8): 7887-7891.

[13] Shumin Feng, Xianghao Shen, Baoyu Hu. Optimization of traffic demand management policy in China: towards a sustainable mode split [J]. Transportation Planning and Technology, 2018, 41 (2): 198-210.

[14] Qi Wang, Jia Wan, Yuan Yuan. Locality constraint distance metric learning for traffic congestion detection [J]. Pattern Recognition, 2018, 75: 272-281.

[15] Zhaolong Ning, Jun Huang, Xiaojie Wang. Vehicular Fog Computing: Enabling Real-Time Traffic Management for Smart Cities [J]. IEEE Wireless Communications, 2019, 26 (1): 87-93. 